\title{
Control de la
}

\section{Administración pública federal mexicana:} la ruptura de la legalidad frente a las cargas públicas

\author{
Guillermo Cambero Quezada'
}

\section{RESUMEN}

El Estado mexicano compromete su buen actuar cuando en la construcción de una obra o en la prestación de un servicio emplea medios que colocan a los particulares, ya sea en su persona o en su patrimonio, en una situación de "riesgo de naturaleza excepcional". La presente investigación muestra cómo estas circunstancias, dada su gravedad, exceden ampliamente las cargas que deben soportar los administrados como contrapartida de los beneficios que se derivan de la ejecución de una obra pública o de la prestación de un servicio. En esta situación, que se conoce como el principio de ruptura de igualdad de los ciudadanos ante la ley y las cargas públicas, la Administración no puede eludir su responsabilidad probando que no tiene culpa.

1 Profesor investigador de la Universidad Autónoma de Guadalajara. Miembro del Sistema Nacional de Investigación (SNI), CONACYT (2017-2019). Profesor visitante de la Facultad de Derecho de la Universidad Bretaña Sur, Vannes, Francia. Doctor y maestro en Derecho Público por la Universidad de Nantes, Nantes, Francia. Licenciado en Derecho por la Universidad de Guadalajara, Guadalajara, México. Correo-e: guillermo.cambero@edu. uag.mx. Enlace ORCID: https://orcid.org/0000-0002-6392-1806. Fecha de recepción: 15 de julio de 2018. Fecha de modificación: 5 de agosto de 2018. Fecha de aceptación: 11 de septiembre de 2018. Para citar el artículo: Cambero Quezada, Guillermo, "Control de la Administración pública federal mexicana: la ruptura de la legalidad frente a las cargas públicas", Revista digital de Derecho Administrativo, Universidad Externado de Colombia, n. ${ }^{\circ}$ 21, 2019, pp. 347-368. DOI: https://doi.org/10.18601/21452946.n21.14 
Palabras clave: responsabilidad patrimonial del Estado, ruptura de la legalidad, responsabilidad sin culpa, indemnización, derecho administrativo mexicano.

\title{
Control Over the Federal Mexican Public Administration: Unlawful and Unequal Discharge of Public Burdens
}

\begin{abstract}
The State is liable when in a public work or in the provision of services it uses means that expose individuals or their patrimonies to an "exceptional risk". This paper aims to show that this causes an unequal discharge of public burdens that largely exceed the benefits derived from the service or work performed. Since the Administration is bared from imposing some people alone to bear public burdens which, in all fairness and justice, should be borne by the public as a whole, strict liability applies.

Keywords: State Pecuniary Liability, Public Wrong, Strict Liability, Compensatory Damages, Mexican Administrative Law.
\end{abstract}

\section{INTRODUCCIÓN}

El derecho administrativo es el derecho de la acción administrativa. Fue concebido y se desarrolló para permitir a la Administración actuar y cumplir sus misiones. Esta característica se explica por el hecho de que la Administración persigue el interés general, que es a la vez su justificación y la explicación de la acción administrativa ${ }^{2}$. Desde esta perspectiva, se definen los alcances actuales la responsabilidad patrimonial del Estado federal mexicano ${ }^{3}$ en el marco de la responsabilidad sin culpa o funcionamiento normal en el servicio, en particular la responsabilidad emanada de una ruptura que ha tenido el ciudadano o el administrado de la legalidad frente a las cargas públicas. En ese sentido, para

2 No hay que confundir dicho concepto con el interés público. Este se define como las necesidades a las cuales la iniciativa privada no puede responder, y que son vitales para la comunidad y para cada uno de sus miembros, dichas necesidades constituyen el dominio propio de la Administración. En contra parte, el motor de la acción administrativa es desinteresada y persigue el interés general o desde una perspectiva filosófica, el bien común. Aunque el contenido del interés general varía de acuerdo con la época y lugar, el objetivo sigue siendo el mismo: la acción administrativa tiende a la satisfacción del interés general. Véase JEAN-JACQUES CheVALLIER, "L'intérêt général dans l'administration française", Revue internationale des Sciences administratives, vol. 41, n. ${ }^{\circ}$ 4, Paris: Sage Publications, 1975, p. 325.

3 En particular, véase a GuILLERMO CAMBERO QueZADA, "La evolución de la responsabilidad patrimonial del Estado en México", Letras Jurídicas. Revista Electrónica de Derecho, n. 21, Guadalajara: Centro Universitario de la Ciénega (Universidad de Guadalajara), 2016. 
admitir la responsabilidad no hay que referirse al hecho de saber si el servicio ha funcionado bien o mal ${ }_{i}$ ya que en el presente supuesto el particular afectado no tendrá que probarlo. Por el contrario, la Administración no podrá eludir la responsabilidad probando que no tiene culpa. Por ende, es suficiente con demostrar el nexo de causalidad entre la acción administrativa y el daño sufrido, y que el daño presenta ciertos caracteres específicos, lo que convertiría un actuar normal o regular de la Administración pública federal mexicana en ilegal, anormal o irregular ${ }^{4}$.

El sistema tiene grandes ventajas para el particular que ha sido víctima del daño, pues no tiene que probar la existencia de la culpa del servicio ni el grado de gravedad que presenta dicha culpa (lo que hace una verdadera responsabilidad objetiva en el sentido del derecho civil). Por tal razón, en la sección 1 analizaremos la responsabilidad patrimonial del Estado en el orden jurídico mexicano, en la sección 2 el origen civil de la teoría de riesgo excepcional aplicado a la ruptura de igualdad de los ciudadanos frente a las cargas públicas como fuente de responsabilidad patrimonial del Estado, y en la sección 3 estudiaremos la aplicación de este último principio en el derecho administrativo desde la óptica del derecho comprado, que puede ser una noción clarificadora para futuras decisiones del Tribunal Federal de Justicia Administrativa (TFJA) ${ }^{5}$, al intentar buscar respuestas sobre la responsabilidad sin culpa de la Administración pública en los diferentes casos que se le someten al respecto.

\section{EL MARCO JURÍDICO MEXICANO DE RESPONSABILIDAD PATRIMONIAL DEL ESTADO}

Para entender la introducción del concepto de la ruptura de la legalidad frente a las cargas públicas en México, es necesario realizar un examen previo del

4 En México existe precedente mediante la tesis aislada, "Responsabilidad patrimonial del Estado. Su objetivo y fines en relación con la prestación de un servicio público", Décima época, Registro: 2003143, Instancia: Tribunales Colegiados de Circuito, Tipo de Tesis: Aislada, Semanario Judicial de la Federación y su Gaceta, libro XVIII, marzo de 2013, tomo 3, Materia(s): Administrativa, Tesis: I.4o.A.35 A (10a.), p. 2077.

5 La creación del TFJA se justificó como un tribunal de instancia administrativa colocado dentro del marco del Poder Ejecutivo (inspirado en los principios de creación de tribunales administrativos en Francia), los cuales eran independientes de la administración "activa", pero no del Poder Judicial, ya que existía, y aún existe, sujeción a los tribunales federales en vía de amparo. Esto es, un tribunal de justicia delegada dentro del Poder Ejecutivo. El TFJA tiene el monopolio la jurisdicción administrativa. Aunque legalmente se ha consolidado como un tribunal de lo contencioso administrativo autónomo (artículo 1, párrafo de la Ley Orgánica del Tribunal Federal de Justicia Administrativa), desde su origen se ha cuestionado su constitucionalidad e independencia del Poder Ejecutivo. Véase, Augusto FERNÁNDEZ SAGARDI, "El Tribunal Fiscal de la Federación. Una visión del foro ante las propuestas de su traslado al Poder Judicial de la Federación", en Lo contencioso administrativo en la reforma de Estado, México: Instituto Nacional de Administración Pública, 2001, p. 43. 
régimen de la responsabilidad patrimonial del Estado ${ }^{6}$, el cual es relativamente nuevo y poco explorado, y por su misma esencia, no cesa de progresar, además de ser complejo y cambiante. Lo anterior se encuentra establecido en la Constitución mexicana, en el artículo 109 último párrafo, el cual estipula que "la responsabilidad del Estado por los daños que, con motivo de su actividad administrativa irregular, cause en los bienes o derechos de los particulares, será objetiva y directa. Los particulares tendrán derecho a una indemnización conforme a las bases, límites y procedimientos que establezcan las leyes". Se analizan las generalidades de la responsabilidad patrimonial del Estado en el marco jurídico mexicano (1.1), y posteriormente se estudia la responsabilidad por falla de servicio que se ha confirmado en la jurisprudencia ${ }^{7}$ del juez mexicano (1.2).

\subsection{Generalidades de la responsabilidad patrimonial del Estado}

La institución de la responsabilidad objetiva y directa del Estado mexicano ha faltado de claridad conceptual y terminológica. La teoría del riesgo ${ }^{8}$ puede ayudar a esta clarificación, ya que la objetividad establece la ausencia de intencionalidad dolosa, es decir, el fundamento de la responsabilidad se encuentra en el hecho que produjo el resultado dañoso, sin importar si este fue cometido con culpa o dolo. Lo relevante para establecer una responsabilidad es la presencia del daño y la relación de causalidad entre el hecho o acción

6 Al respecto, véase Álvaro Castro Estrada, "Análisis jurídico de la reforma constitucional que incorporó la responsabilidad patrimonial del estado a la constitución mexicana", Cuestiones Constitucionales, n. ${ }^{\circ}$ 8, México: UnAm, 2003, p. 205.

7 La jurisprudencia en México surge de la práctica del juicio de garantías o amparo, el cual es un recurso que proporciona el sistema jurídico mexicano a los particulares que han visto violentado sus derechos fundamentales por una autoridad administrativa o judicial, y se traduce en las interpretaciones y consideraciones jurídicas integrativas uniformes que hace la autoridad judicial mexicana designada para tal efecto por la ley (tribunales superiores o la Suprema Corte de Justicia de la Nación), respecto de uno o varios puntos de derecho especiales y determinados que surgen de un cierto número de casos concretos semejantes que se presenten, en la inteligencia de que dichas consideraciones e interpretaciones son obligatorias para los inferiores jerárquicos de las mencionadas autoridades y que expresamente señala la ley. Además, la jurisprudencia constituye un medio de desentrañar el sentido de la ley, para el efecto de que los juzgadores puedan aplicar esta última en forma debida y con criterio uniforme, precisamente cuando pronuncien el fallo correspondiente. Véase Ignacio Burgoa, Juicio de amparo, 29. a ed., México: Editorial Porrúa, 1992, p. 821. Para ampliar el estudio al respecto, véase Miguel Carbonell, "Sobre el concepto de jurisprudencia en el sistema jurídico mexicano", Boletín Mexicano de Derecho Comparado, n. ${ }^{\circ}$ 87, México: UNAM, 1996, p. 721.

8 Camile Broyelle, "Le risque en droit administratif 'classique'"', RDP, n. ${ }^{\circ}$ 6, Paris: Lextenso, 2008, p. 1514. 
ejercida de manera irregular y el daño ${ }^{9}$. No es necesario buscar si la persona quien realizó la acción lo hizo de una forma dolosa o negligente ${ }^{10}$. Para indemnizar el perjuicio solo basta con demostrar por parte del particular la realización de una actividad administrativa irregular y el nexo de causalidad entre ese actuar o esa omisión y el daño. En ese sentido, la Suprema Corte de Justicia mexicana (SCJN), por jurisprudencia, establece que la responsabilidad objetiva es aquella "en la que el particular no tiene el deber de soportar los daños patrimoniales causados por una actividad irregular del Estado, entendida esta como los actos de la administración realizados de manera ilegal o anormal, es decir, sin atender a las condiciones normativas o a los parámetros creados por la propia Administración"11.

En relación con lo directo, es la consecuencia al artículo 1927 del Código Civil federal mexicano, que establecía una responsabilidad indirecta del Estado, ya que este tenía la obligación de responder

del pago de los daños y perjuicios causados por sus servidores públicos con motivo del ejercicio de las atribuciones que les estén encomendadas. Esta responsabilidad será solidaria tratándose de actos ilícitos dolosos, y subsidiaria en los demás casos en los que solo podrá hacerse efectiva en contra del Estado cuando el servidor público

9 Debiendo entender que la misma está desvinculada sustancialmente de la negligencia, dolo o intencionalidad, propios de la responsabilidad subjetiva e indirecta, regulada por las disposiciones del derecho civil. La jurisprudencia mexicana mantiene el principio de que "cuando el artículo 113 constitucional (hoy 109, último párrafo) alude a que la responsabilidad patrimonial objetiva del Estado surge si este causa un daño al particular'con motivo de su actividad administrativa irregular', abandona toda intención de contemplar los daños causados por la actividad regular del Estado, así como cualquier elemento vinculado con el dolo en la actuación del servidor público, a fin de centrarse en los actos propios de la administración que son realizados de manera anormal o ilegal, es decir, sin atender a las condiciones normativas o a los parámetros creados por la propia administración". Véase "Responsabilidad Patrimonial del Estado. Diferencia entre Responsabilidad Objetiva y Subjetiva", Novena Época, Registro: 169428, Instancia: Pleno, Tipo de Tesis: Jurisprudencia, Semanario Judicial de la Federación y su Gaceta, tomo XXVII, junio de 2008, Materia(s): Constitucional, Tesis: P./J. 43/2008, p. 719

10 "La responsabilidad objetiva prescinde en absoluto de la conducta del sujeto, de su culpabilidad $_{i}$ en ella se atiende única y exclusivamente al daño producido. Basta este para que su autor sea responsable cualquiera que haya sido su conducta, haya habido o no culpa o dolo de su parte. Es el hecho perjudicial, el hecho liso y llano y no el hecho culpable o doloso el que genera la responsabilidad". ARTURO AleSSANDri RodrícueZ, De la responsabilidad extracontractual en el derecho civil, Santiago: Imprenta Universal, 1981, p. 56.

11 "Responsabilidad patrimonial del Estado objetiva y directa. Su significado en términos del Segundo párrafo del Artículo 113 de la Constitución Política de los Estados Unidos Mexicanos", Novena época, Registro: 169424, Instancia: Pleno, Tipo de Tesis: Jurisprudencia, Semanario Judicial de la Federación y su Gaceta, tomo XXVII, junio de 2008, Materia Constitucional, Tesis: P./J. 42/2008, p. 722. 
directamente responsable no tenga bienes o los que tenga no sean suficientes para responder de los daños y perjuicios causados por sus servidores público ${ }^{12}$.

Este descansa en la teoría de la culpa y el concepto de daño ilícito. Lo directo significa que cuando en el ejercicio de sus funciones el Estado genere daños a los particulares en sus bienes o derechos, estos podrán reclamarla directamente al órgano administrativo, sin tener que demostrar la ilicitud o el dolo del servidor que causó el daño reclamado, sino únicamente la irregularidad de su actuación, y sin tener que demandar previamente al servidor público una indemnización.

El siguiente elemento de la responsabilidad patrimonial se encuentra en la actividad irregular, y es la que ha generado el mayor debate. El fundamento de mantener un sistema de responsabilidad patrimonial basado en un actuación irregular por parte de la administración pública federal únicamente se explica por el dictamen de adición del párrafo segundo del antiguo artículo 113 (hoy 109, último párrafo) de la Constitución, emitido por Senado, el cual establece lo siguiente: "No se considera prudente, por el momento, incluir la actividad normal o regular de la Administración, dado que ese criterio no ha cobrado gran aceptación en nuestro derecho; sin perjuicio, por supuesto, de que el rumbo que tomen estas nuevas disposiciones permitan una revisión posterior sobre este punto"13. Ahora bien, la SCJN. mediante jurisprudencia de 2014. confirma lo expuesto por el Senado en el año 2001, y establece que

esa delimitación podría estar sujeta a revisión posterior con base en el desarrollo de la regulación de responsabilidad patrimonial en nuestro país, lo cierto es que extender su ámbito protector a los actos normales o regulares de la Administración pública solo puede tener efectos mediante reforma constitucional, por lo que esa ampliación protectora no puede establecerse a virtud de ley reglamentaria u otras normas secundarias, pues con ello se contravendría la esencia que inspiró esta adición constitucional $1^{14}$.

Reafirmado así que la responsabilidad patrimonial del Estado en México excluye por mandato de ley los casos donde el daño es producto del funcionamiento

12 Artículo 1927 del Código Civil Federal, hoy derogado.

13 Dictamen preliminar aprobatorio de las Comisiones Unidas de Puntos Constitucionales, Gobernación y de Estudios Legislativos de la Cámara de Senadores que aprueba la adición constitucional de la responsabilidad patrimonial en México.

14 "Responsabilidad patrimonial del Estado. Su regulación constitucional excluye la actividad administrativa regular o lícita de los entes estatales", Décima época, Registro: 2008114 , Instancia: Segunda Sala, Tipo de Tesis: Jurisprudencia, Gaceta del Semanario Judicial de la Federación, libro 13, diciembre de 2014, tomo I, Materia Administrativa, Tesis: 2a./J. 99/2014 (10a.), p. 297. 
regular o lícito de la actividad pública, a diferencia de otros sistemas jurídicos que incluyen los actos normales o regulares de la propia Administración.

\subsection{La falla DEL SERVICIO EN MÉXICO: CREACIÓN JURISPRUDENCIAL}

A pesar de lo antes expuesto, la responsabilidad por falla de la Administración pública mexicana surge de manera temerosa, y esto significa que esta debe responder de sus propias fallas, lo que se conoce como falla de servicio, que en términos generales corresponde a una falla de la Administración como organización. Esta responsabilidad se fundamenta en la idea de que basta que el particular manifieste una mala marcha general y anónima del servicio, que el servicio, en su organización o en su funcionamiento, ha sido defectuoso, y que el daño proviene como una consecuencia de lo anterior. Se juzga directamente al servicio público ${ }^{15}$, no al funcionario ${ }^{16}$ (responsabilidad objetiva). Las fallas cometidas por los agentes al servicio del Estado, esto incluye no únicamente a los servidores públicos nombrados, designados o contratados por el Estado, sino, en general, a toda persona que desempeñe un empleo, cargo o comisión de cualquier naturaleza en la Administración pública, cuando le hayan ocasionado daños y perjuicios a los bienes y derechos al particular mexicano derivado de faltas o infracciones administrativas graves. Entonces, existe la obligación y la responsabilidad derivada de la realización objetiva del hecho

15 En México, no existe una definición legal del servicio público, sin embargo, la SCJN lo ha tratado de definir mediante las siguientes notas características: "1. El servicio público debe consistir en una actividad prestacional, es decir, una actividad que tiende a otorgar a otros una ventaja, un bien, un beneficio, etcétera, de cualquier naturaleza y, por lo tanto, varía el ingreso de quien la recibe o disminuye los gastos en que pudiera incurrir en el supuesto de no recibirlo. 2. Esta actividad es asumida por la Administración pública de manera expresa y concreta, lo que significa que es reservada en exclusiva en cuanto a la dirección y organización a un órgano estatal y que el ejercicio de esa actividad requiere de autorización previa del Estado expresada con un acto de autoridad. En este sentido, las actividades en las que se permite la concurrencia de particulares sin esta previa autorización no son servicios públicos. 3. La Administración pública realiza la actividad de servicio público en forma directa o indirecta, es decir, valiéndose de la concesión, aunque la legislación mexicana no es consistente en la denominación que otorga a esta figura jurídica, puesto que en algunas leyes administrativas se emplea el término autorización, cuando se refiere a la prestación de un servicio público. 4. El servicio público siempre debe tender a la satisfacción del interés general. 5. El servicio público se presta conforme a un régimen de derecho público, especial y propio que lo particulariza e identifica frente a otras actividades administrativas y cuyas características son su generalidad, uniformidad, continuidad, regularidad, obligatoriedad y subordinación a la administración pública. Por lo tanto, no puede estar sujeto a un régimen de derecho privado en cuanto a su prestación". Novena época, Registro: 177794, Instancia: Tribunales Colegiados de Circuito, Tipo de Tesis: Aislada, Semanario Judicial de la Federación y su Gaceta, tomo XXII, julio de 2005, Materia: Administrativa, p. 1538.

16 Françoise Llorens-FraYsSE, "Le poids de la faute dans la responsabilité administrative", Droits, n. ${ }^{\circ}$ 5, Paris: PuF, 1987, p. 66. 
dañoso, imputable al Estado, y no la motivación subjetiva del agente de la Administración. Sin embargo, no toda la falla del servicio genera automáticamente la responsabilidad de la Administración. Hace falta un cierto grado de insuficiencia en el mismo, que varía según los servicios, los lugares y las circunstancias ${ }^{17}$.

Los Tribunales Colegiados de Circuito, mediante tesis aislada ${ }^{18}$, introducen la falla de servicio en las actividades irregulares ${ }^{19}$ estableciendo lo siguiente: "actividad administrativa irregular es aquella que por acción u omisión incumpla con las obligaciones legales establecidas o por el funcionamiento defectuoso de un servicio, lo que en la doctrina y la jurisprudencia en Francia se conoce la faute de service o falla del servicio" ${ }^{120}$, es decir, el funcionamiento anormal de un servicio público por falla o deficiencia ${ }^{21}$. Pese a lo antes expuesto, existe una evolución deseable, así una responsabilidad sin falla o sin culpa de la Administración pública federal, y que se abre camino dentro del océano jurídico del derecho administrativo federal mexicano.

\section{ORIGEN Y EVOLUCIÓN DE LA LEGALIDAD DE LOS CIUDADANOS FRENTE A LAS CARGAS PÚBLICAS}

En el derecho administrativo mexicano se diferencia la teoría del riesgo de la ruptura de legalidad (2.1). Esta diferenciación permite estudiar la evolución de la teoría de la ruptura de la legalidad (2.2) y su integración en el sistema jurídico mexicano (2.3).

17 JaQues Moreau, "Les présomptions de faute en droit administratif de la responsabilité", Gouverner, administrer, juger, Paris: Daloz, 2002, p. 685.

18 La Suprema Corte y los Tribunales, al fijar un criterio en una tesis aislada, estudia aquellos aspectos que el legislador no precisó, e integra a la norma los alcances que, no contemplados en esta, se producen en una determinada situación. Es únicamente clarificadora para el juzgador, más no obligatoria. Miguel Carbonell, óp. cit., p.724.

19 Véase Jean Claude Hélin, Faute de service et préjudice dans le contentieux de la responsabilité pour illégalité, Tesis de doctorado, Universidad de Nantes, Nantes Francia, 1969, p. 16.

20 Décima época, Registro: 2003143, Instancia: Tribunales Colegiados de Circuito, Tipo de Tesis: Aislada, Fuente: Semanario Judicial de la Federación y su Gaceta, libro xvIII, marzo de 2013, Tomo 3, Materia Administrativa, Tesis: I.4o.A.35 A (10a.), p. 2077.

21 La falla en el servicio se desprende de la prestación de un servicio estatal, que al no ser prestado en la forma debida genera un daño, derivándose que el Estado tenga que responder directamente por ese daño ocasionado cuando sea causado por una falla en el servicio, lo cual se configura como nexo causal. Frente a este punto vale la pena aclarar que para que el Estado cumpla su función, esto es los servicios que tiene a su cargo, debe hacerlo por intermedio de individuos y entidades que muchas veces son imposibles de identificar al ocurrir el daño y por ello el Estado responde directamente. Guillermo Cambero QueZada, L'instauration du Système de Responsabilité de L'administration Publique au Mexique. Analyse de Droit Comparé, Tesis doctoral, Nantes: Universidad de Nantes, 2011, p. 106. 


\subsection{DifERENCIA ENTRE LA TEORÍA DEL RIESGO Y LA RUPTURA DE LEGALIDAD}

La responsabilidad sin culpa ${ }^{22}$, en ocasiones, no se puede vincular a la idea del riesgo creado derivada de la responsabilidad objetiva, teniendo su base en el derecho civil, la cual establece que la obligación de reparar el daño nace del solo hecho de haberlo causado, sustituyéndose la idea de culpa por la de riesgo ${ }^{23}$ y creando una relación obligatoria de patrimonio a patrimonio, para resarcir los daños causados en la víctima ${ }^{24}$; pero esta hipótesis en derecho civil requiere que el daño por resarcir sea precisamente causado con motivo del empleo de mecanismos, instrumentos, aparatos, etcétera, y no por causas extrañas a ellos, e imputables a terceros que nada tienen que ver con los que los manejan. La diferencia esencial entre la teoría del riesgo y la de la culpa es que en esta última, para que una persona incurra en responsabilidad, es preciso que sea autora del hecho dañoso y que lo haya cometido con culpa (intencionalmente o por imprudencia), y en aquella, basta que a la persona le sea imputable el hecho, para que incurra en responsabilidad, por la sola circunstancia de haberse producido el daño; independientemente de la ilicitud en la conducta asumida por el causante del daño y que se traduce en la necesidad de repararlo, salvo prueba de haberse producido por negligencia inexcusable de la víctima. Por tanto, en una como en otra hipótesis, solo puede hacerse efectiva la responsabilidad contra quien directa o indirectamente sea el autor del hecho material que causó el daño, y en derecho administrativo, este sería imputable a la Administración pública ${ }^{25}$.

En México, la teoría del riesgo se encuentra reconocida legalmente en materia administrativa, tanto en la Constitución ${ }^{26}$ como la Ley Federal de Responsabilidad Patrimonial del Estado ${ }^{27}$, al aceptar la responsabilidad objetiva del Estado. Y también ha sido confirmada por la Suprema Corte de Justicia de la Nación por jurisprudencia, la cual estableció lo siguiente:

La diferencia entre la responsabilidad objetiva y la subjetiva radica en que mientras esta implica negligencia, dolo o intencionalidad en la realización del daño, aquella se apoya en la teoría del riesgo, donde hay ausencia de intencionalidad dolosa. Por otra parte, del contenido del proceso legislativo que dio origen a la adición indicada, se advierte que [...] el Constituyente [...] decidió centrar la calidad objetiva de la responsabilidad patrimonial del Estado a los actos realizados de manera

Ibíd., p. 62.

23 Camille Broyelle, óp. cit., pp. 1513-1524.

24 Véase, Jean Waline, "L'évolution de la responsabilité extracontractuelle des personnes publiques", EDCE, n. ${ }^{\circ} 46$, Paris: La documentation française, 1988, p. 460.

25 JeAn Marie CotTeret, "Le régime de la responsabilité pour risque en droit administratif", in J. Rivero, Études de droit public, Paris: Cujas, 1964, p. 85

26 Artículo 109, último párrafo.

27 Artículo 1. 
irregular, debiendo entender que la misma está desvinculada sustancialmente de la negligencia, dolo o intencionalidad, propios de la responsabilidad subjetiva e indirecta, regulada por las disposiciones del derecho civil. Así, cuando el artículo 113 constitucional alude a que la responsabilidad patrimonial objetiva del Estado surge si este causa un daño al particular "con motivo de su actividad administrativa irregular", abandona toda intención de contemplar los daños causados por la actividad regular del Estado, así como cualquier elemento vinculado con el dolo en la actuación del servidor público, a fin de centrarse en los actos propios de la administración que son realizados de manera anormal o ilegal, es decir, sin atender a las condiciones normativas o a los parámetros creados por la propia Administración ${ }^{28}$.

Derivado de lo anterior, en la teoría del riesgo ${ }^{29}$, en materia administrativa, existe ausencia de intencionalidad dolosa, esto es, el fundamento de la responsabilidad se encuentra en el hecho que produjo un resultado dañoso, sin importar si este fue cometido con culpa o dolo. Lo relevante para establecer una responsabilidad es la presencia del daño y la relación de causalidad entre el hecho o acción ejercida por la Administración pública, y el daño que esta genera $^{30}$. No es necesario buscar si el ente administrativo que realizó la acción lo hizo de una forma dolosa o negligente ${ }^{31}$. Para indemnizar el perjuicio solo basta con demostrar dicha realización de la Administración pública y el nexo de causalidad entre ese actuar o esa omisión y el daño. Sin embargo, la teoría del riesgo no podría explicar por sí misma otros supuestos de responsabilidad del Estado, en donde existe una necesidad de reparar los daños y perjuicios de naturaleza especial y anormal que manifiestan una ruptura de legalidad frente a las cargas públicas. Los efectos de un acto conforme al principio de legalidad conciernen a un grupo específico de ciudadanos, en particular cuando la actividad que ejercían antes de la intervención de la Administración pública mediante su actuar, sus condiciones de realización se ven profundamente modificadas. La ruptura de legalidad resultado de este actuar, el cual no es ilegal, conlleva una responsabilidad sin falta de la Administración. Este principio fue reconocido por los altos tribunales del país al establecer que

28 "Responsabilidad patrimonial del Estado. Diferencia entre responsabilidad objetiva y subjetiva", Novena época, Registro: 169428, Instancia: Pleno, Tipo de Tesis: Jurisprudencia, Semanario Judicial de la Federación y su Gaceta, tomo XXVII, junio de 2008, Materia(s): Constitucional, Tesis: P./J. 43/2008, p. 719.

29 Camille Broyelle, óp. cit., p. 1514.

30 Pere Joan Torrent I Ribert, "La responsabilidad patrimonial de las Administraciones públicas", Colección Estudios y Monografías, Madrid: Editorial Mapfre, 1995, p. 46.

31 "La responsabilidad objetiva prescinde en absoluto de la conducta del sujeto, de su culpa-

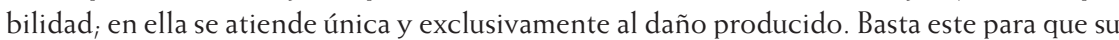
autor sea responsable cualquiera que haya sido su conducta, haya habido o no culpa o dolo de su parte. Es el hecho perjudicial, el hecho liso y llano y no el hecho culpable o doloso el que genera la responsabilidad", Arturo Alessandri RodríGuez, óp. cit., p. 43. 
La razón de la responsabilidad patrimonial es propiciar y garantizar, en primer lugar, que la actividad administrativa sea regular y que la gestión pública se preste conforme a ciertos estándares de calidad, lo que encierra en sí mismo un derecho fundamental a una eficiente Administración pública, pues si se incumple con esos estándares se tiene garantizado el derecho a la indemnización. Por ello, cuando en la prestación de un servicio público se causa un daño en los bienes y derechos de los particulares por la actuación irregular de la Administración pública, se configura, por una parte, la responsabilidad del Estado y, por otra, el derecho de los afectados a obtener la reparación, ya que la actividad administrativa irregular del Estado comprende también lo que la doctrina denomina faute de service (funcionamiento anormal de un servicio público por falla o deficiencia) $)^{32}$.

Partiendo de lo anterior, el principio de ruptura de legalidad frente a las cargas públicas estipula que, con base al interés general, algunos ciudadanos sufren un daño que el resto de la población no lo ha sufrido, configurando un funcionamiento anormal del servicio público ${ }^{33}$. La única forma de restablecer el equilibrio es indemnizar el perjuicio ocasionado. Lo que nos lleva a analizar los principios fundamentales de la legalidad frente a las cargas públicas.

\subsection{Naturaleza de LA LEGALIDAD FRENTE A LAS CARGAS PÚBLICAS}

Inicialmente, la igualdad ante la ley implicaba solamente igualdad en el contenido de esta en cuanto norma general, abstracta y atemporal, además de dotar de igual capacidad jurídica a todas las personas sin distinción alguna, porque buscaba eliminar los privilegios y arbitrariedades generados por los regímenes monárquicos. El principio de legalidad de los ciudadanos frente a la ley encuentra su fundamento en Francia, como el resultado de una protección efectiva en contra del poder del monarca (o Administración pública realizando actos de "rey"), particularmente en la Declaración de los Derechos del Hombre y del Ciudadano de 1789, en el artículo 6, el cual establece:

La ley es la expresión de la voluntad general. Todos los ciudadanos tienen derecho a contribuir a su elaboración, personalmente o a través de sus representantes. Debe ser la misma para todos, tanto para proteger como para sancionar. Además, puesto que todos los ciudadanos son iguales ante la ley, todos ellos pueden presentarse y ser elegidos para cualquier dignidad, cargo o empleo públicos, según sus capacidades y sin otra distinción que la de sus virtudes y aptitudes.

32 "Responsabilidad patrimonial del Estado. Su objetivo y fines en relación con la prestación de un servicio público", Décima época, Registro: 2003143, Instancia: Tribunales Colegiados de Circuito, Tipo de Tesis: Aislada, Semanario Judicial de la Federación y su Gaceta, libro XVIII, marzo de 2013, tomo 3, Materia(s): Administrativa, Tesis: I.4o.A. 35 A (10a.), p. 2077.

33 Al respecto, véase Michel Paillet, La faute du service public en droit administratif, Paris: LGDJ, 1980. 
En ese sentido, y en épocas más reciente dentro del ámbito de la convencionalidad, la Declaración Universal de Derechos Humanos de 1948 establece en su artículo 7 que: "Todos son iguales ante la ley y tienen, sin distinción, derecho a igual protección de la ley. Todos tienen derecho a igual protección contra toda discriminación que infrinja esta Declaración y contra toda provocación a tal discriminación". Por su parte, el Pacto Internacional de Derechos Civiles y Políticos de 1966 indica que

Todas las personas son iguales ante la ley y tienen derecho sin discriminación a igual protección de la ley. A este respecto, la ley prohibirá toda discriminación y garantizará a todas las personas protección igual y efectiva contra cualquier discriminación por motivos de raza, color, sexo, idioma, religión, opiniones políticas o de cualquier índole, origen nacional o social, posición económica, nacimiento o cualquier otra condición social.

De igual manera, la Convención Americana sobre Derechos Humanos (Pacto de San José) de 1969 establece en el artículo 24, de la igualdad ante la ley, lo siguiente: "Todas las personas son iguales ante la ley. En consecuencia, tienen derecho, sin discriminación, a igual protección de la ley". En el marco del derecho mexicano, este principio se encuentra en la Constitución mexicana en los siguientes artículos: 4, primer párrafo, y el cual establece: "El varón y la mujer son iguales ante la ley" y 13, primer párrafo, que ordena: "Nadie puede ser juzgado por leyes privativas ni por tribunales especiales" ${ }^{\prime \prime 34}$. La igualdad ante la ley implica que los órganos encargados de dicha labor no deben hacer ninguna diferencia que el derecho a aplicar no establezca previamente, esto es, que la igualdad ante la ley obliga a que esta sea aplicada de modo igual a todos aquellos que se encuentran en la misma situación, sin que el aplicador pueda establecer diferencia alguna debido a las personas, o de circunstancias que no sean precisamente las presentes en las normas. Esto significa que "en

34 Pese a que este artículo no contiene un enunciado explícito de la igualdad ante la ley, por mucho tiempo se ha considerado en México que en él se encuentra contenido de manera específica. El sustento de esa afirmación es en esencia, según lo reflejan los criterios jurisprudenciales que así lo establecen, lo ocurrido durante los debates del Congreso Constituyente de 1856-1857 respecto al proyecto de artículo 2, que posteriormente se transformaría en el artículo 13 de la Constitución, el cual incluía el enunciado: "Todos los habitantes de la República, sin distinción de clases ni de origen, tienen iguales derechos". Enunciado que al final fue eliminado del texto de dicho artículo por los debates que generó, y por ello, se ha dicho por años que ahí está contenida la igualdad ante la ley. Al respecto, véase: JosÉ Ovalle Favela, "Comentario al artículo 13 constitucional", en Constitución Política mexicana comentada y concordada, 16. ${ }^{a}$ ed., México: UNAM - Instituto de Investigaciones Jurídicas, 2000, p. 154. 
todos los aspectos relevantes, las personas deben ser tratadas y consideradas de igual manera a menos que haya una razón suficiente para no hacerlo" ${ }^{\prime \prime 5}$.

Lo anterior se traslada al derecho público, en particular a la igualdad frente al servicio público, principio de valor constitucional en México, el cual es la aplicación a este campo del principio general de igualdad de todos ante la ley proclamada por la Constitución mexicana, en su artículo 4 y 13. Significa que todos ciudadanos tienen el mismo derecho a acceder al servicio, participa por igual en la carga financiera resultante del servicio (igualdad de tarifas, por ejemplo), y finalmente debe ser tratado de la misma manera que cualquier otro usuario del servicio. En consecuencia, "la originalidad de la responsabilidad del Estado es la misión de un sistema de servicio público frente a una violación de la legalidad en dicho servicio ${ }^{136}$. Desde este punto de vista teórico, se considera que el principio de igualdad ante las cargas públicas es el que sirve de base general para todos los supuestos de responsabilidad del poder público. Esto es, cualquier daño que se analice como una carga, que las víctimas no deben sufrir indebidamente, el Estado debe reparar mediante la aplicación de las reglas de la responsabilidad patrimonial ${ }^{37}$.

Así, se afirma que el Estado actúa con base al interés general ${ }^{38}$. Es por el interés general que las autoridades establecen disposiciones administrativas legales (decretos, reglamentos, leyes, tratados). En ocasiones, en la búsqueda del interés general se genera una carga en detrimento de una o más personas, es decir, generando un daño grave y especial que no ha sufrido el resto de la colectividad. Esta carga crea una ruptura en la igualdad de todos los ciudadanos frente a las cargas públicas, en detrimento del particular, víctima de la carga indebida. El razonamiento del juez es simple: es inevitable sacrificar el interés de una o más personas por el interés general, sin compensación. El juez restablecerá el equilibrio al asumir la responsabilidad sin culpa del órgano de la Administración pública que creó la carga anormal en detrimento de un ciudadano. Este principio ha sido confirmado por los tribunales superiores.

\subsection{Principio de leGalidad frente a las Cargas públicas} EN EL DERECHO MEXICANO

De hecho, existe la idea de que la base fundamental de este régimen de responsabilidad es en gran medida "metalegal", es decir, se justifica en la existencia 2000, p. 177. 
de un sentimiento de compensación necesaria de las víctimas en ciertas configuraciones particulares, en nombre de la equidad ${ }^{39}$. Efectivamente, hay daños y perjuicios que sería ilógico no compensar al ciudadano.

El principio de correlación entre cargas y beneficios abarca los casos en los que el interés general se beneficia de una actividad y, como consecuencia, debe soportar la carga de la indemnización por daños y perjuicios que la Administración causó al ciudadano que no ha sido beneficiado. En cuanto al principio de igualdad ante las cargas públicas, permite dar cuenta de los casos en que las autoridades deben compensar a las personas por una operación correspondiente a la satisfacción de un interés público y mantenida durante un período regular ${ }^{40}$.

Siguiendo esta lógica, los tribunales colegiados del país han realizado en fechas recientes un análisis de la Constitución Política de los Estados Unidos Mexicanos, y establecen que la Carta Magna:

revela que frente al catálogo de derechos humanos que caracterizan a los gobernados ante el poder público, existe también un conjunto de obligaciones a su cargo, derivadas de las restricciones y limitaciones a esos derechos y de las exigencias que impone el funcionamiento correcto de las instituciones públicas, entre las cuales se hallan las manifestaciones de ciertas potestades que, por un lado, someten a los gobernados a ciertos regímenes específicos de sujeción y, por otro, les imponen ciertas conductas o, incluso, la extracción de ciertos bienes o riqueza. Así, es necesario distinguir la situación que guarda una persona en el régimen general de sujeción propio de cualquier gobernado, de aquella que le corresponde cuando se encuentra sometida a uno especial, asociado a su condición o a su actividad. En el régimen general, las personas tienen, por ejemplo, ciertas obligaciones que se rigen por el principio de igualdad ante las cargas públicas, las cuales derivan simplemente de su pertenencia a la población de un Estado ${ }^{41}$.

El mismo tribunal colegiado, siguiendo la lógica de la igualdad frente a las cargas públicas, agrega que

las obligaciones son producto de un régimen especial de sujeción, es decir, de un conjunto de normas, principios, reglas y directrices que pesan sobre un grupo de personas, debido a su situación particular con respecto al interés social o al orden público. [...] Finalmente, existe un tercer supuesto en donde la persona se ve afectada por el ejercicio individual y concreto de cierta potestad pública de ejercicio

39 Éric Souteyrand, "La responsabilité de l'administration", AJDA, Paris: Dalloz, 1999, p. 92.

40 Pierre Delvolvé, Le principe d'égalité devant les charges publiques, Paris: LGDJ, 1969, p. 187.

41 "Regímenes de sujeción constitucionalmente previstos. Sus características", Décima época Registro: 2013672, Instancia: Tribunales Colegiados de Circuito, Tipo de Tesis: Aislada, Gaceta del Semanario Judicial de la Federación, libro 39, febrero de 2017, tomo III, Materia(s): Constitucional, Administrativa, Tesis: 1.2o.A.E.51 A (10a.), p. 235. 
latente, que se traduce en una lesión individualizada que crea una situación jurídica individualizada, como ocurre con la expropiación. De esta manera, es importante distinguir cuándo ciertos deberes a cargo de una persona tienen su origen en un régimen general propio de cualquier gobernado, cuándo examinarlos en uno especial asociado a su condición estatutaria y cuándo en un acto privativo singularizado ${ }^{42}$.

Al respecto de la ruptura de legalidad de las cargas públicas, no basta que el daño sea cierto, actual, causalmente ligado a la existencia de un servicio público u obra pública y evaluable ${ }^{43}$. Ha de ser, además, como en toda hipótesis de responsabilidad sin falta, especial y anormal. Especial porque debe particularizarse a la víctima afectada, y no a todos los miembros de una comunidad (las finanzas públicas de los Estados modernos no tendrían suficientes fondos para reparar daños de colectividades completas afectadas por una obra pública), por ejemplo: la privación a los vecinos de las vías públicas como el derecho de acceso a sus inmuebles o las molestias (ruidos, humos, olores) objetivamente excesivas. Anormal, ya que debe exceder los inconvenientes inherentes al funcionamiento de un servicio que se impone a toda vida en colectividad, ejemplo: los daños corporales y la destrucción o deterioro de la propiedad, son siempre anormales. No se resarce el daño si los inconvenientes que sufre el colindante o vecino de la obra pública son compensados por las ventajas que le reporta la proximidad del inmueble. Y, también la indemnización se excluye si la victima ha podido prever la producción del daño y, pese a todo, adquiere o construye un inmueble próximo o colindante con una obra pública. En tal caso se considera que asume los inconvenientes derivados de la vecindad del inmueble. Evidentemente, los tribunales administrativos deben resolver en función de las circunstancias particulares de cada caso, lo que introduce en la materia un cierto grado de contingencia y relatividad. Ante el panorama antes descrito, la aceptación legal y jurisprudencial de la igualdad ante las cargas públicas abre la posibilidad para el juez administrativo mexicano de establecer una responsabilidad para la Administración pública sin falla o culpa, invocando en sus argumentaciones la ruptura de legalidad ante las cargas públicas y que se pueden materializar en diferentes supuestos que se analizaran a continuación desde la óptica del derecho comparado. 


\section{LOS CASOS DE RUPTURA DE LA IGUALDAD ANTE LAS CARGAS PÚBLICAS}

Las obras emprendidas debido al interés general, una colaboración aportada en el servicio público, las actividades peligrosas que satisfacen una necesidad de servicio público, una decisión legal de la policía, una ley o un tratado que, por definición, satisface un interés colectivo no debe ocasionar un perjuicio particular para un individuo u otro, que sería la víctima de una ruptura de igualdad ante las cargas impuestas a todos. La igualdad es, por lo tanto, la base de una responsabilidad sin falta o culpa ${ }^{44}$ y existe una obligación de reparación del daño, por lo que se examinará la responsabilidad generados por hechos administrativos regulares (3.1), por los daños permanentes resultado de obras públicas (3.2) y por leyes y tratados internacionales (3.3).

\subsection{RUPTURA DE IGUALDAD POR DECISIONES ADMINISTRATIVAS REGULARES}

Se concibe bajo la idea que un acto administrativo emanado de la Administración pública de manera regular o legal puede generar un daño, que, bajo la estructura del principio antes analizado, se tiene la posibilidad de una indemnización por parte del Estado. Si bien es verdad, la legislación mexicana, como se analizó, no acepta el supuesto de una responsabilidad por una irregularidad, sin embargo, existen excepciones en la práctica, en la cual Estado, en su actividad regular, genera una ruptura de igualdad de las cargas, y genera daños, lo cual convierte el acto en una verdadera irregularidad. En el derecho comparado, en particular en Francia, podemos encontrar diversos ejemplos de la aplicación del hecho generador de esta responsabilidad, y generalmente son medidas de control de función de policía-administración que, por el hecho de aplicarlas, tienen una consecuencia para el particular, convirtiéndose en un perjuicio anormal, grave y especial ${ }_{i}$ ejemplo: someter una actividad profesional al control del Estado, reglamentos de circulación en la vía pública para determinados vehículos, etcétera.

También, el derecho comparado proporciona ejemplo de daños generados por actos administrativos de orden no reglamentarios, los cuales pueden originarse cuando la policía se rehúsa a la ejecución de una orden judicial de expulsión de personas de un terreno por el riesgo de desestabilizar el orden público superiores a los que conlleva la no ejecución de la decisión. En la medida que ese rechazo a aplicar la decisión se prolongue, puede generar un daño al propietario del bien inmueble o terreno obstruido que desde hace tiempo que ha sido ocupado ilegalmente, y el derecho a reparación puede llevarse a 
cabo si se demuestra un perjuicio de carácter anormal y especial ${ }^{45}$. Es por la abstención de tomar una decisión que la Administración será considerada responsable, mientras que su abstención se justifica sin embargo por la necesidad del orden público y por el interés general.

En ese orden ideas, otro ejemplo lo proporciona el alcalde de un municipio francés que decidió reglamentar el tráfico de vehículos en las carreteras de montaña y reservar algunos caminos a los excursionistas a caballo, mientras que otros podrían ser utilizados por los peatones. Es así como el dueño de una tienda de recuerdos demanda al municipio porque la decisión de convertir el camino frente a su tienda únicamente en paso para jinetes de caballos le genera una gran afectación a su negocio. Aquí, el daño es compensado, incluso si el acto es derivado de un poder reglamentario del alcalde, aunque la idea de la ruptura de legalidad frente a las cargas públicas, el daño realmente debe ser especial y grave ${ }^{46}$.

Por último, existen dos hipótesis sobre decisiones individuales en Francia. La primera es la negativa en ejecutar una orden judicial, en la cual se niega el desalojo a los huelguistas en una empresa ${ }^{47}$. El segundo, es la ausencia de un proceso judicial, en la cual la autoridad no puede restablecer del orden público combinado con una abstención de las autoridades policiales locales. Han existido una serie de aplicaciones de esta hipótesis para huelguistas o manifestantes paralizando vías fluviales, puertos marítimos o aeropuertos. Son las necesidades del orden público las que justifican esta abstención de la intervención del Estado, sin embargo, generan daños especiales, y el Estado (federal o estatal) o el municipio deberán compensar.

\subsection{RUPTURA DE IGUALDAD POR DAÑOS PERMANENTES RESULTADO DE LAS OBRAS PÚBLICAS}

El daño previsto por este supuesto no está relacionado con la ocurrencia de un accidente (ya que este supuesto es responsabilidad por culpa o irregular,

45 En particular, ver el caso francés "Couitéas", Consejo de Estado francés (CE), 30 noviembre 1923. En este caso, el propietario de un terreno obtiene por sentencia la expulsión de 8000 personas instaladas en dicho terreno. La asistencia de la fuerza policial se le niega a la vista de los graves disturbios engendrados por la operación. El CE confirma la existencia de un "peligro para el orden y la seguridad" (y, por lo tanto, el hecho de que el rechazo no tiene la culpa la Administración). Sin embargo, el CE admite, no obstante, que el daño resultante "no debe existir, pero si supera una determinada duración, se considerara una carga que normalmente incumbe al interesado". Después de un tiempo, el CE considera que la Administración es responsable (esta es la condición para que el daño sea lo suficientemente serio, además del hecho de que es especial). Si el rechazo no está justificado, hay una falla, y luego entramos al terreno de la culpa. La jurisprudencia francesa admite la no intervención, pero mediando una compensación.

46 Consejo de Estado francés, 22 febrero de 1963, "Commune de Gavarnie".

47 Consejo de Estado francés, 3 de junio de 1938, "Société La cartonnerie e Imprimerie St. Charles". 
prevista por el sistema de leyes mexicanas), sino que es el resultado de la existencia misma de una obra pública o la ejecución de obras públicas. Esto puede ser una molestia causada por el ruido del tráfico en una autopista construida por encima de los dos metros de altura de una propiedad ${ }^{48}$ o el cierre de un estacionamiento debido a la transformación de una calle en una pasarela o vía peatonal ${ }^{49}$. En ese sentido, el daño, por su naturaleza anormal y especial, excede el que se expone al mismo, a nombre del interés general, por lo que cualquier ciudadano residente puede ser reparado sin la necesidad de demostrar culpa alguna. La Administración no puede escapar de la responsabilidad demostrando que no ha cometido ninguna falla o culpa.

Los casos de aplicación de este sistema de responsabilidad sin culpa son, a su vez, muy frecuentes en otros países. Sin embargo, si la obra pública existió antes de la instalarse el solicitante de un posible daño, no puede obtener una compensación por daños resultantes de una molestia a la que ha estado expuesto, a menos que las condiciones de operación de la obra pública hayan cambiado.

El daño permanente también puede ser el resultado de la ausencia o paro sin justificación alguna (o con justificación) de obras públicas realizadas por la Administración y de la cual es responsable. En el ámbito de personas con discapacidad, se ha llegado a considerar que el daño resultante de la inadecuación de un edificio judicial a la discapacidad de un abogado, se asume la responsabilidad sin culpa del Estado si presenta un carácter serio y especial cuya carga excede la que normalmente corresponde a cualquier ciudadano para soportar ${ }^{50}$.

\subsection{RUPTURA DE IGUALDAD POR LEYES Y TRATADOS INTERNACIONALES}

Aunque aún sin concepción y sin elaboración doctrinal dentro del marco nacional mexicano, la responsabilidad por aplicación de leyes nacionales la encontramos en el ejemplo francés de una ley aprobada por el Parlamento ${ }^{51}$. La ley prohibía el uso de otros productos distintos de la crema natural o los productos lácteos, lo cual genero un daño a una empresa que solicito una indemnización por parte del Estado, ya que tuvo que renunciar a su actividad. Por lo que el máximo tribunal administrativo francés (Consejo de Estado) estableció la responsabilidad sin culpa del Estado por el daño causado por el legislador. Pero la implementación de este régimen de responsabilidad es muy

48 Consejo de Estado francés, 5 de noviembre de 1982, "Sté. des Autoroutes du Sud de France", Lebon, p. 767.

49 Consejo de Estado francés, 16 oct. 1992, "SA Garage de Garches", Lebon, p. 1303.

50 Véase Consejo de Estado francés, 22 octubre 2010, Mme Bleitrach, RFDA 2011, p. 141, cond. Roger-Lacan, AIDA 2010, p. 2207, chrono D. Botteghi y A. Lallet, RDSS, 2011, p. 151, nota H. Rihal.

51 Consejo de Estado francés, 14 enero 1938, "Société La Fleurette". 
difícil que pueda aparecer, ya que únicamente han existido cinco solicitudes desde 1938 en Francia, debido a las condiciones estrictas del supuesto. De hecho, el daño debe ser especial, pero esta condición no se cumple a menudo porque las leyes establecen principios generales. Por consiguiente, dentro de esta hipótesis se excluye la responsabilidad por razón de las leyes, cuando el propósito de la ley es evitar un régimen discriminatorio, particularmente en asuntos económicos, o si está destinado a proteger un interés muy general y preeminente, como el de la economía nacional en su conjunto. En este caso, se considera que el daño colateral que podría haber sido causado por la ley no puede ser reparado o compensado.

Esta responsabilidad puede ser incurrida bajo las mismas condiciones como resultado de convenciones internacionales ${ }^{52}$, la cual solo ha sido admitido tres veces hasta la fecha en el sistema francés. Los ejemplos son la de un propietario que no podía obtener la expulsión de un diplomático que no pagaba alquiler en razón a un acuerdo de sede entre Francia y una organización internacional ${ }^{53}$. Recientemente, se ordenó al Estado francés pagar una reparación por el monto equivalente de la indemnización por despido al personal de Air Afrique Compagnie que residía en Francia y que habían sido privados de su trabajo por los acuerdos internacionales firmados entre Francia y Costa de Marfil ${ }^{54}$. Finalmente, fue sentenciado el Estado francés a la indemnización de un empleado diplomático, debido a las convenciones internacionales, regularmente ratificadas, otorgándole inmunidad diplomática ${ }^{55}$.

\section{CONCLUSIONES}

La Administración pública puede causar daños, lesionando los derechos de los particulares, por actos legales y sin falla o culpa creados por la propia Administración, los cuales aún no han sido considerados por el derecho mexicano. En unos o en otros casos encontramos siempre actos jurídicos u operaciones materiales realizados por sus servidores, o hechos acaecidos durante el funcionamiento del servicio, y unos daños derivados de los actos u omisiones de los servidores o del funcionamiento del servicio. Razones de equidad, de justicia distributiva, de seguridad social, reclaman la indemnización de los daños sufridos por los particulares a causa del desarrollo de la actividad administrativa, aunque sea con regularidad y fortalecer la noción de ruptura de legalidad frente a las cargas públicas. Así, es deseable una reforma constitucional en México

52 Consejo de Estado francés, 30 de marzo de 1966, "Compagnie générale d'énergie radioélectrique", GAJA, n. ${ }^{\circ} 78$.

53 Consejo de Estado francés, 29 de octubre de 1976, "Dame Burgat", Lebon, p. 452.

54 Consejo de Estado francés, 29 de diciembre de 2004, Almayrac, AJDA, 2005, p. 427.

55 Consejo de Estado francés, febrero de 2011, "Mlle Susilawati", RFDA 2011. 573, conclusiones C, Roger-Lacan. 
para la integración de los algunos actos regulares o el funcionamiento normal del servicio, mediante un serio debate a profundidad y tomando en cuenta los factores de hacienda pública en el país. La jurisprudencia nacional también debe ser un motor esencial para la evolución del derecho administrativo, ya que ha sido esta la que ha establecido la constitucionalidad, su definición y alcances, así como la integración de otros conceptos, como la falla del servicio y legalidad frente a las cargas públicas. Pero la jurisprudencia aún tiene mucho camino por recorrer y profundizar en conceptos relativos a la materia de responsabilidad patrimonial del Estado, ya que pareciera que el juez nacional es temeroso en la aplicación de dichos conceptos. El presente trabajo es una contribución al entendimiento global de la responsabilidad patrimonial del Estado, el reforzamiento de los derechos de los gobernados y la eficiencia en la administración pública.

\section{BIBLIOGRAFÍA}

Alessandri Rodríguez, Arturo. De la responsabilidad extracontractual en el derecho civil, Santiago: Imprenta Universal, 1981.

Broyelle, Camile. "Le risque en droit administratif 'classique'", RDP, n. ${ }^{\circ}$ 6, Paris: Lextenso, 2008.

Burgoa, Ignacio. Juicio de amparo, 29. a ed., México: Editorial Porrúa, 1992.

Cambero Quezada, Guillermo. "La evolución de la responsabilidad patrimonial del Estado en México", Letras jurídicas (Revista Electrónica de Derecho), n. ${ }^{\circ}$ 21, Guadalajara: Centro Universitario de la Ciénega, Universidad de Guadalajara, 2016.

Cambero Quezada Guillermo. L'instauration du Système de Responsabilitéde L'administration Publique au Mexique. Analyse de Droit Comparé, Tesis doctoral, Nantes: Universidad de Nantes, 2011.

Carbonell, Miguel. "Sobre el concepto de jurisprudencia en el sistema jurídico mexicano", Boletín Mexicano de Derecho Comparado, n. ${ }^{\circ}$ 87, México: unam, 1996.

Castro Estrada, Álvaro. "Análisis jurídico de la reforma constitucional que incorporó la responsabilidad patrimonial del estado a la constitución mexicana", Cuestiones Constitucionales, n. ${ }^{\circ}$ 8, México: UNAM, 2003.

Chapus, René. Droit administratif général, vol. II, Paris: LGDJ, 2001.

CheValiter, JeAn-Jacques. "L'intérêt général dans l'administration française", Revue internationale des Sciences administratives, vol. 41, n. ${ }^{\circ}$ 4, Paris: Sage Publications, 1975 
Cotteret Jean Marie. "Le régime de la responsabilité pour risque en droit administratif", in J. Rivero, Études de droit public, Paris: Cujas, 1964.

Debard, Thierry. "L'égalité des citoyens devant les charges publiques, fondement incertain de la responsabilité administrative", Chronique, n. ${ }^{\circ}$ 23, Paris: Dalloz, 1987.

Delvolvé, Pierre. Le principe d'égalité devant les charges publiques, Paris: LGDJ, 1969.

Fernández Sagardi, Augusto. "El Tribunal Fiscal de la Federación. Una visión del foro ante las propuestas de su traslado al Poder Judicial de la Federación", en Lo Contencioso Administrativo en la Reforma de Estado, México: Instituto Nacional de Administración Pública, 2001.

García Morillo, Joaquín. "La cláusula general de igualdad", en Derecho constitucional. El ordenamiento constitucional. Derechos y deberes de los ciudadanos, vol. I, Valencia: Tirant lo Blanch, 2000.

Hélin, Jean Claude. Faute de service et préjudice dans le contentieux de la responsabilité pour illégalité, Tesis doctorado, Universidad de Nantes, Nantes, 1969.

Llorens-Fraysse, FranÇOISE. "Le poids de la faute dans la responsabilité administrative", Droits, n. ${ }^{\circ}$ 5, Paris: PUF, 1987.

Morand-Deviller, Jaqueline. Cours Droit Administratif, Paris: LGDJ, 2015.

Moreau, Jaques. "Les présomptions de faute en droit administratif de la responsabilité", Gouverner, administrer, juger, Paris: Daloz, 2002.

Moreau, Jaques. La responsabilité administrative, 2. a ed., Paris: PUf, 1986.

Ovalle Favela, José. "Comentario al artículo 13 constitucional", en Constitución Política mexicana comentada y concordada, 16. ${ }^{\text {a }}$ ed., México: UNAM - Instituto de Investigaciones Jurídicas, 2000.

Paillet, Michel. La faute du service public en droit administratif, Paris: LGDJ, 1980.

Paillet, Michel. La responsabilité administrative, Paris: Dalloz, 1996.

Papin, Jean-Philippe. "Les ouvrages d'E.D.F. et du G.D.F. peuvent-ils occasionner des troubles d'agrément indemnisables?", CJEG, Paris: 1984.

PUISOYE, JACQUES. "Le principe d'égalité devant les charges publiques comme fondement direct de la responsabilité", AJDA, Paris: Dalloz, 1964.

Rougevin-Baville, Michel. La responsabilité administrative, Paris: Hachette, 1992. 
Souteyrand, ÉRIC. "La responsabilité de l'administration", AJDA, Paris: Dalloz, 1999.

Torrent i Ribert, Pere Joan. "La responsabilidad patrimonial de las Administraciones públicas", Colección Estudios y Monografías, Madrid: Editorial Mapfre, 1995.

Waline, JeAn. "L'évolution de la responsabilité extracontractuelle des personnes publiques", EDCE, n. ${ }^{\circ}$ 46, Paris: La documentation française, 1988. 